\title{
Why Do Not Physicians Attend Hospital Cardiopulmonary Resuscitation Training?
}

\author{
Kasper G Lauridsen ${ }^{1-3}$ \\ Rikke Højbjerg ${ }^{4}$ \\ Anders S Schmidt ${ }^{1,3}$ \\ Bo Løfgren (ID) ${ }^{1,3,5}$ \\ 'Department of Internal Medicine, \\ Randers Regional Hospital, Randers, \\ Denmark; 'Emergency Department, \\ Randers Regional Hospital, Randers, \\ Denmark; ${ }^{3}$ Research Center for \\ Emergency Medicine, Aarhus University \\ Hospital, Aarhus, Denmark; ${ }^{4}$ Emergency \\ Department, Aarhus University Hospital, \\ Aarhus, Denmark; ${ }^{5}$ Department of \\ Clinical Medicine, Aarhus University, \\ Aarhus, Denmark
}

Introduction: Cardiopulmonary resuscitation (CPR) training is mandatory in most hospitals. Despite this, some hospital staff do not attend CPR training on a regular basis, but the barriers to training attendance are sparsely investigated. This study aimed to investigate CPR course attendance, barriers to participation, and possible initiatives to increase CPR course attendance. Methods: Physicians from one university hospital and one regional hospital in the Central Denmark Region were included. Questionnaires were handed out at daily staff meetings at departments of internal medicine and surgery.

Results: In total, 233 physicians responded (response rate: 92\%, male: 54\%). Overall, 32\% of physicians had not attended CPR training at the hospital. Mean ( \pm standard deviation) time since the last CPR course participation was $17( \pm 3)$ months. Frequent barriers to attending courses included not knowing when courses are conducted $(70 \%)$ and where to sign up for training $(45 \%)$. The majority $(60 \%)$ of physicians responded that the reason why they prioritize course participation is to be professionally updated. In contrast, $16 \%$ stated that they had sufficient CPR skills and therefore CPR training was unnecessary. Physicians stated that the following factors would improve CPR training participation: an annual day protected (no clinical work) for course attendance (72\%), use of short booster sessions (49\%), shorter courses combined with e-learning (51\%) and shorter courses held over 2 days (46\%).

Conclusion: One-third of physicians did not attend hospital CPR training at two Danish hospitals. Several barriers to course participation exist, of which course registration seems to be a crucial factor. Alternative CPR training methods may help improve training participation.

Keywords: in-hospital cardiac arrest, cardiopulmonary resuscitation, resuscitation training, hospital administration, basic life support

\section{Introduction}

In-hospital cardiac arrest (IHCA) occurs frequently with an incidence of 1-10 per 1000 hospital admissions and has a poor survival rate at $15-30 \% .^{1-5}$ The cardiopulmonary resuscitation (CPR) does most often not meet guideline recommendations for chest compression rate and -depth and ventilation rate. ${ }^{6,7} \mathrm{CPR}$ training is essential in order to improve CPR quality and has been identified as the primary focus area in order to improve survival following cardiac arrest. ${ }^{8-10}$ Moreover, efficient CPR training is associated with improved survival following IHCA. ${ }^{11}$

Following CPR training, resuscitation skills are known to decay as soon as after 3-9 months. ${ }^{12-14}$ Frequent CPR retraining is therefore mandatory in many hospitals. However, some hospital staff do not attend CPR training on a regular basis, and physicians are known to attend training less often than nurses. ${ }^{15}$ Therefore, the actual CPR training attendance rate among hospital physicians is unknown.
Correspondence: Bo Løfgren

Tel +4578420000

Email bl@clin.au.dk 
Several barriers to attending CPR training may exist, and the motivation for CPR training attendance is currently understudied. Moreover, novel teaching methods such as e-learning have been shown to be efficient, timesaving, and cost-effective when training CPR. ${ }^{16,17}$ Other methods such as low-dose and high-frequency CPR training have been shown to improve skill retention of inhospital pediatric providers. ${ }^{18}$ It is unknown if novel CPR training initiatives can increase CPR course attendance among hospital physicians.

Accordingly, this study aimed to investigate in-hospital CPR course attendance, barriers for participating in CPR training and possible initiatives to increase CPR course attendance among hospital physicians.

\section{Methods}

\section{Study Design}

This is a cross-sectional questionnaire study. Physicians from one university hospital (regional invasive center, number of hospital beds: 992, number of annual hospitalizations: 96.199, number of full-time physicians employed at the hospital: 1.586) and one regional hospital (number of hospital beds: 232, number of annual acute hospitalizations: 37.665 , number of full-time physicians employed at the hospital: 578) in the Central Denmark Region were included. Physicians were mandated to participate in a half-day local basic life support (BLS) course or a full-day local advanced life support (ALS) course at least every other year, depending on the department of deployment, which reflects practices in other Danish hospitals. ${ }^{19}$ CPR training participation was mandatory, although there were no sanctions if a physician did not participate in the training. Questionnaires were handed out to physicians at morning staff meetings at internal medicine departments and non-medical departments. We chose these departments as most cardiac arrests occur outside the ED and outside the ICU in Denmark. ${ }^{4,20}$ We chose not to include departments with a very low risk of cardiac arrests, eg Department of Pathology and Department of Radiology. We sampled physicians at morning staff meetings as we believed that there would be no systematic differences between those being on service on a randomly selected day and those not being on service. Participants were able to ask clarifying questions to a study investigator throughout completion of the questionnaire. Participation was voluntary, and participants were guaranteed that no answers were revealed to employers or other parties. Participants were included in a draw to win a bottle of wine in each department (value: 10
Euros). Information on the number of cardiac arrests occurring in each hospital department was obtained by contacting the resuscitation officer in each hospital.

According to Danish law, no consent form or approval from the Danish National Committee on Biomedical Research Ethics was required. Distribution of questionnaires was approved by the hospital administration in each hospital and the chief physician in each department.

\section{Study Questionnaire}

The questionnaire collected information on 1) Demographics including age, sex, area of specialty, postgraduate clinical experience, and clinical position. 2) Information on the time since the last CPR course attendance and the type of previous CPR training. 3) Barriers to course attendance including course registration and clinical workload. 4) Preferred length of CPR courses. 5) Professional output of CPR courses. 6) Personal motivation for attending CPR courses. 7) CPR training initiatives that could improve CPR course attendance.

Information on the time since the last CPR training was provided as number of years and months and information on course registration as a barrier to attending CPR training was dichotomously assessed (yes/no). Clinical workload as a barrier for attending CPR training, the professional output of CPR training, and motivational factors were assessed using a 5-point Likert scale (disagree, partially disagree, neither agree nor disagree, partially agree, agree). Preferred course length was assessed using categories ( $\leq 1$ hour, 2 hours, 3 hours, 4 hours, $>4$ to 6 hours, $>6$ to 8 hours, $>8$ hours). Information on initiatives to improve CPR training was dichotomously assessed (yes/no). The content and specific wording of the questionnaire was carefully reviewed by all the authors and afterwards tested for face-validity by three resuscitation officers.

\section{Statistical Analysis}

Physicians were grouped as A) junior physicians (medical students working as locum physicians and residents) and senior physicians (fellows and attending physicians), and B) from the Department of Internal Medicine or non-medical departments (surgical departments, gynecology/obstetrics, and pediatrics). Data were analyzed for normality using histograms and Q-Q plot analysis. Non-normally distributed data were logarithmically transformed and were only reported as raw data with median (25th percentile; 75 th percentile) if not normally distributed after logarithmic transformation. Normally distributed data were reported as mean ( \pm standard 
deviation (SD)) and were analyzed using Student's $t$-test. Assumptions behind the Student's $t$-test were assessed using standard deviation testing. The ratio for time since last CPR training between junior- and senior physicians is based on a Student's $t$-test of logarithmically transformed data (ie geometric means). Categorical data were compared using Chisquared test. Data were analyzed using Stata version 13.0 (StataCorp LP, College Station, TX, USA).

\section{Results}

We distributed 254 questionnaires to physicians at morning staff meetings at 6 departments of internal medicine and 6 departments of surgery with various incidences of cardiac arrests (Table 1). In total, 233 (response rate: 92\%) responded. Baseline characteristics of physicians are shown in Table 2.

In total, $158(68 \%)$ had attended CPR training in the hospital of present employment. More physicians from the departments of internal medicine (75\%) had attended CPR training in the hospital of current employment compared with physicians from non-medical departments (57\%), risk ratio 1.4 (95\% confidence interval: $1.1-1.8, \mathrm{p}=0.007)$. Mean $( \pm \mathrm{SD})$ time since last CPR training was $17.2( \pm 3.2)$ months. Junior physicians had more recent CPR training (mean 6.5 months (95\% confidence interval (CI): 4.4-9.6)) compared with senior physicians (mean 21.7 months (95\% CI: 18.5-25.3), ratio: 3.3 (95\% CI: $2.3-4.8, \mathrm{p}<0.001)$ ). There was no statistical difference in time since last training between physicians from departments of internal medicine (mean 16.6 months (95\% CI: 12.7-21.7)) and non-medical departments (mean 17.5 months (95\% CI: $14.3-21.4)$ ), ratio 0.95 (95\% CI: 0.68-1.32, $\mathrm{p}=0.76)$.
Course registration was a major barrier as only few physicians knew where to sign up for CPR training or when courses were conducted (Table 3). This regarded physicians from non-medical departments in particular. Overall, 60 (26\%) physicians agreed or partly agreed that the clinical workload is a barrier for course participation. More physicians from non-medical departments $(n=36$ $(42 \%))$ agreed or partly agreed that the clinical workload is a barrier for course participation compared with 24 (17\%) of physicians from departments of internal medicine $(p<0.001)$. In total, 19 physicians $(13 \%)$ from departments of internal medicine and $26(31 \%)$ of physicians from non-medical departments disagreed or partly disagreed that the clinical department administrators take CPR training into consideration when planning the work schedule $(p=0.001)$. Only $11(5 \%)$ physicians reported that the course duration was a barrier to participation. When asked about the optimal course length, physicians reported an optimal course length of $4(2 ; 6-8)$ hours. The median optimal course length for physicians from departments of internal medicine was 4-6 (3; 6-8) hours and 2 $(1 ; 4)$ hours for physicians from non-medical departments. Overall, $120(52 \%)$ agreed or partially agreed that their professional output of CPR training was good, while 7 (3\%) disagreed or partially disagreed.

The most prevalent motivational factor for course participation was being professionally updated, while few would be motivated by a pay-raise for course participation (Figure 1). Several training initiatives would improve course participation, according to physicians (Figure 2).

Table I Included Departments and Cardiac Arrest Incidence

\begin{tabular}{|l|c|c|}
\hline Regional Hospital & Cardiac Arrests Within Last Two Year & Responses \\
\hline Department of Internal Medicine & 62 & 25 \\
Department of Pediatrics & 0 & 11 \\
Department of Orthopedic Surgery & 10 & 14 \\
Department of Abdominal Surgery & 8 & 5 \\
Department of Gynecology and Obstetrics & 2 & 8 \\
\hline University Hospital & & 49 \\
\hline Department of Internal medicine: Cardiology & 149 & 32 \\
Department of Internal medicine: Endocrinology & 32 & 21 \\
Department of Internal medicine: Neurology & 11 & 15 \\
Department of Internal medicine: Hematology & 10 & 33 \\
Department of Abdominal Surgery & 36 & 12 \\
Department of Cardio-thoracic Surgery & 27 & 8 \\
Department of Blood Vessel Surgery & 6 & \\
\hline
\end{tabular}

Note: Data are presented as numbers. 
Table 2 Physician Characteristics

\begin{tabular}{|l|c|c|c|}
\hline & Physicians Overall & Departments of Internal Medicine & Non-Medical Departments \\
\hline Age (years) & $42.7 \pm 10.4$ & $42.2 \pm 10.5$ & $43.4 \pm 10.3$ \\
\hline Male & $122(54)$ & $75(54)$ & $47(52)$ \\
\hline Median clinical experience (years) & $12(7 ; 22)$ & $12(7 ; 22)$ & $13(8 ; 23)$ \\
\hline Years at current hospital & $2.5(0.8 ; 10.0)$ & $2.8(0.8 ; 10.0)$ & $2.3(0.8 ; 9.0)$ \\
\hline $\begin{array}{l}\text { Clinical position } \\
\text { Locum physician }\end{array}$ & $4(2)$ & $1(1)$ & $3(3)$ \\
Resident & $43(18)$ & $31(22)$ & $12(13)$ \\
Fellow & $61(26)$ & $42(30)$ & $57(63)$ \\
Attending & $124(53)$ & $68(48)$ & $9(10)$ \\
\hline Previous ERC ${ }^{\text {a }}$ ALS ${ }^{b}$ training & $45(19)$ & $36(25)$ & $7(8)$ \\
\hline Previous ERC EPLS ${ }^{c}$ training & $10(4)$ & $3(2)$ & $5(5)$ \\
\hline Cardiac arrest team member & $46(20)$ & $41(29)$ & $0(0 ; 1)$ \\
\hline Cardiac arrests treated within last year & $1(0 ; 3)$ & $1(0 ; 5)$ & \\
\hline
\end{tabular}

Notes: Categorical variables are shown as numbers (\%) and continuous variables are shown as mean \pm standard deviation or median (quartile I; quartile 3 ). ${ }^{a}$ European Resuscitation Council. ${ }^{b}$ Advanced life support. 'European Pediatric Life Support.

\section{Discussion}

We found that one-third of hospital physicians did not attend CPR training in the hospital where they are currently employed. Several barriers to course participation exist, of which course registration seems to be a crucial factor. The major motivational factor for course participation was to be professionally updated. Several CPR training initiatives were reported to improve respondents' course participation.

While most physicians attended CPR training during their education, only one-third attended a CPR course in the hospital of current employment, despite CPR training being a mandatory requirement. Local training may be important in order to be familiar with local procedures and equipment as well as the hospital cardiac arrest telephone number and cardiac arrest team composition that is known to vary between hospitals. ${ }^{21-23}$ Moreover, a simulation-based study found that CPR training in a hospital environment can improve skills during IHCA compared with standard basic life support (BLS) training. ${ }^{24}$

Another critical factor for CPR performance is the time since the last retraining. CPR skills rapidly decay after only 3-9 months ${ }^{13,14,25}$ whereby CPR skills may be seriously deteriorated after 17 months being the mean time since the last CPR training in our study. Accordingly, international guidelines now recommend that organizations consider the need for more frequent retraining than every $12-24$ months. ${ }^{26-28}$ Notably, previous findings of retraining intervals for hospital staff in Northern Europe varied from four months ${ }^{29}$ to one year ${ }^{30}$ and two to three years. ${ }^{19}$ Our findings show that

Table 3 Barriers to CPR Training

\begin{tabular}{|l|c|c|}
\hline \multicolumn{1}{|c|}{ Course Registration Factors } & Departments of Internal Medicine & Non-Medical Departments \\
\hline I know when courses are conducted & $53(37)$ & $15(16)$ \\
Information about courses is sufficient & $60(42)$ & $36(40)$ \\
I know where to sign up for courses & $84(59)$ & $39(43)$ \\
Course registration is easy & $51(36)$ & $24(26)$ \\
I am relieved from clinical duties with salary to participate & $105(74)$ & $38(42)$ \\
My department signs me up for course registration & $42(30)$ & $19(21)$ \\
If I do not participate, I will receive a reminder & $47(33)$ & $25(27)$ \\
\hline
\end{tabular}

Note: Number (\%) of physicians answering yes to the statements on course registration. 
A Cardiac arrest occurs so infrequently that CPR training is not necessary

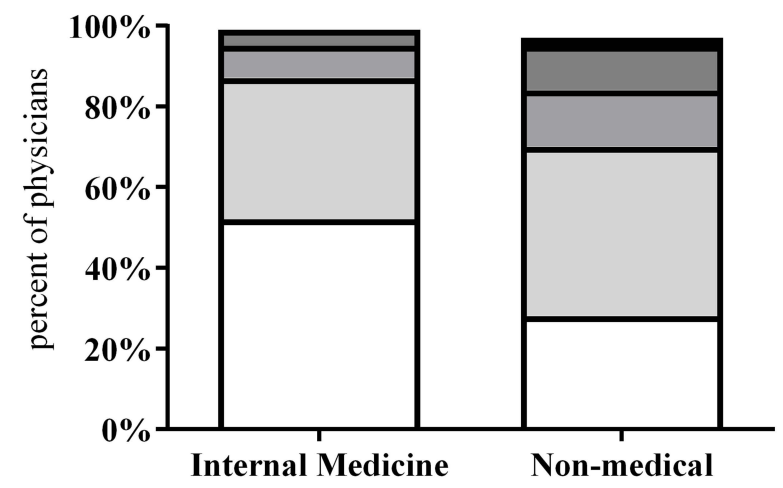

C I prioritize to participate to be professionally updated

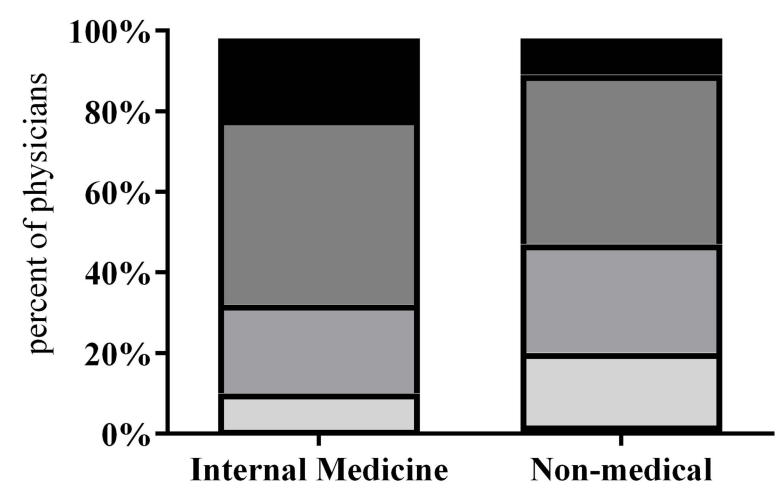

E I would participate more if participation increased my salary

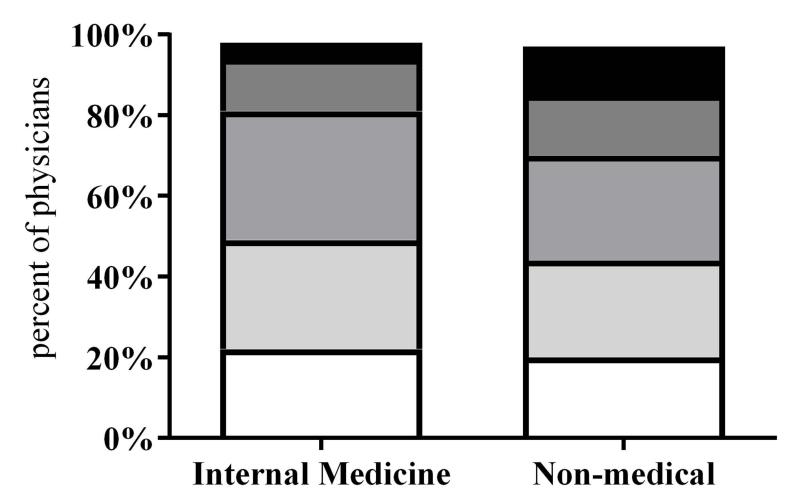

B I have sufficient CPR skills

training is therefore not necessary

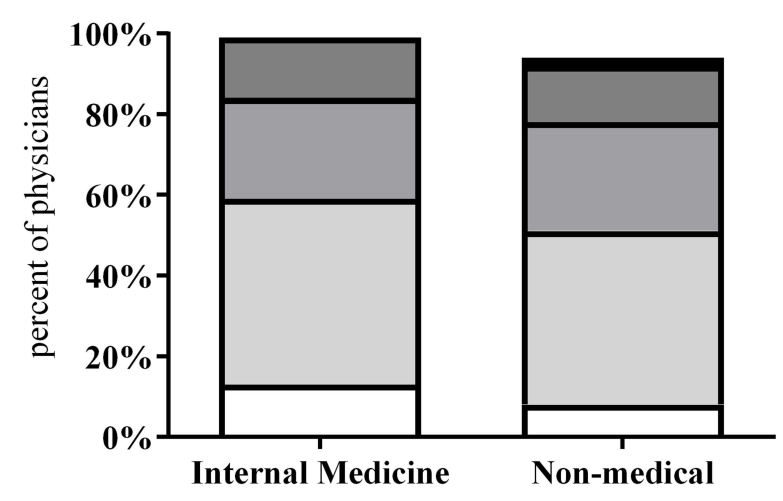

D No other physicians in my department participates in hospital CPR training

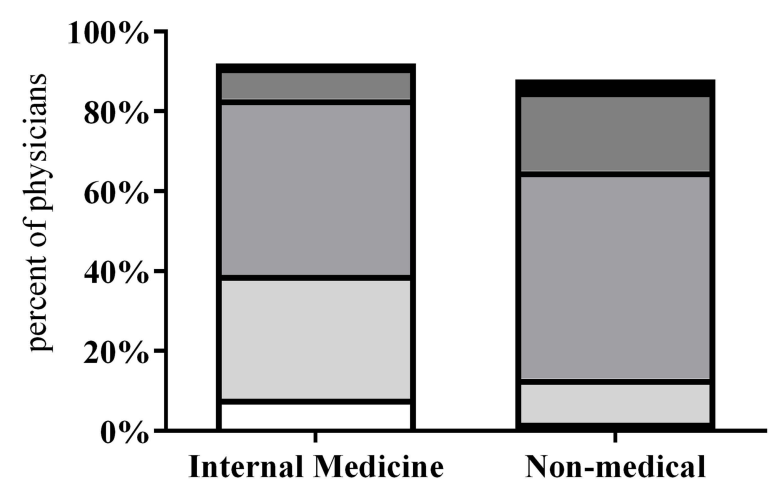

F It should not be allowed to work as a clinician without valid CPR certificate

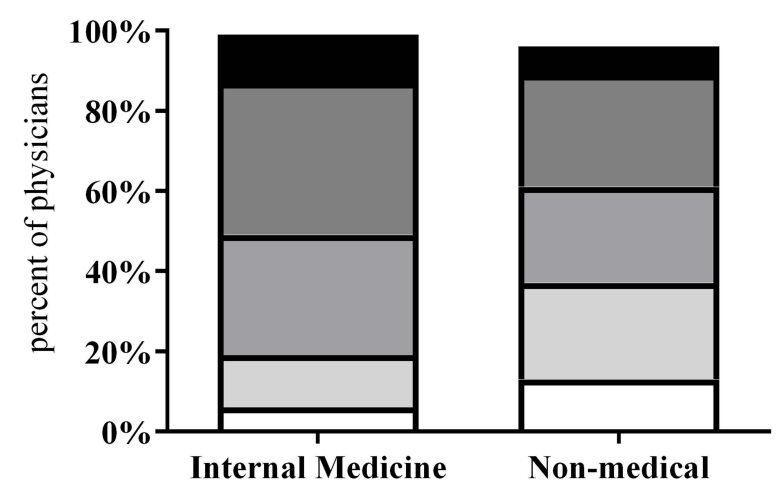

Figure I Motivational factors for CPR training. Responses are shown as percent of physicians agreeing in each statement. Number (\%) of physicians not responding to each question: (A) 3 (I), (B) 6 (3), (C) 6 (3), (D) 22 (9), (E) 6 (2), (F) 5 (2). $\square$, Disagree; $\square$, Partly disagree; $\square$, Neither agree or disagree; $\square$, Partly agree; $\square$, Agree.

differences may be due to, eg, clinical experience as junior physicians have a remarkably shorter time since last retraining when compared to senior physicians. This may be due to frequent changes in employment place for junior physicians. Accordingly, retraining may be needed when starting clinical work at a new hospital. Moreover, they are more often a part of the cardiac arrest team, ${ }^{29}$ which could influence frequency of training as well. 


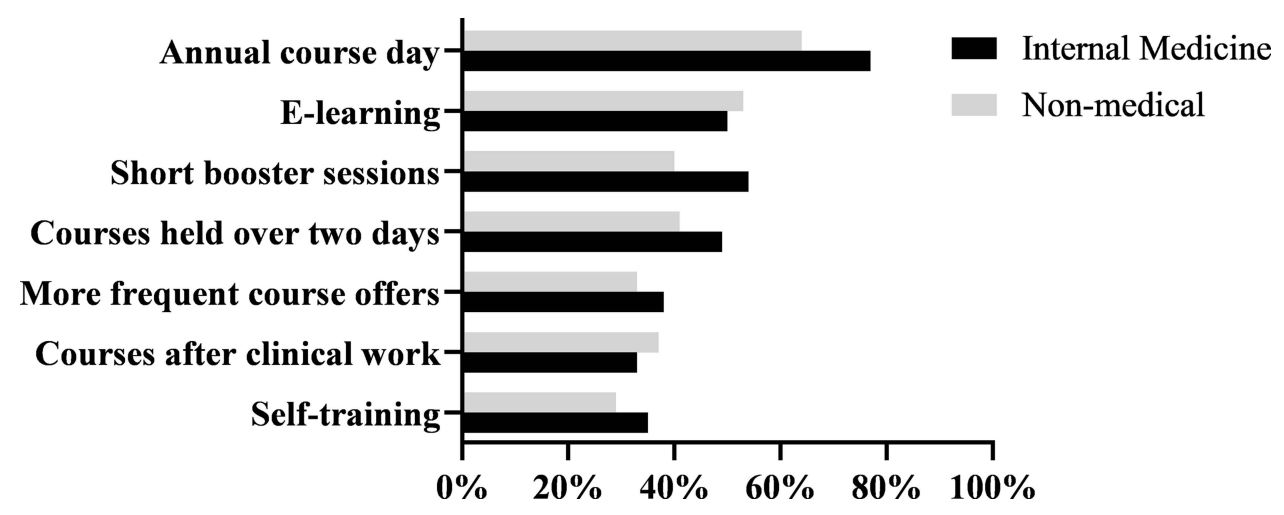

Figure 2 Percent of physicians reporting that each initiative would increase their participation in hospital CPR training.

Our findings from many physicians stating that they do not know when courses are being held may reflect a lack of awareness about CPR training. This regarded physicians from departments of surgery in particular. The lack of awareness is also implied in the findings of several physicians not knowing if the department will cover salary for participation in CPR training. Reducing these problems may include increasing information and advertisement of hospital CPR training to physicians and/or further demanding department chairs to ensure that all employed physicians have completed CPR training. Department administrators may play a crucial role in ensuring that physicians attend CPR training, as not all physicians are motivated to attend CPR training. Incentives to hospital administrations could be by, eg, charging payment for CPR training from the department's budget if physicians are not participating in CPR training currently paid for by the overall hospital funding. This may at least increase the number of physicians receiving reminder mails if they do not participate in CPR training, which we found to be less than one third of physicians in this study. Another approach may be by looking at the US healthcare system, where physicians are required to be CPR certified in order to work as a hospital physician. Interestingly, we found that more than half of physicians from departments of internal medicine agreed or partly agreed in the statement that it should not be possible to work in the hospital without certification in CPR training, whereas fewer physicians from non-medical departments agreed on this.

The most dominating motivational factor to participate in CPR training was being professionally updated. In contrast, only one in five were motivated by a pay rise for course participation. This corresponds well to findings by Hopstock et al showing that a dominating motivational factor is that each individual knows the professional importance of training the skills. ${ }^{31}$ Notably, more physicians from non-medical departments tend to state that cardiac arrest occurs so rarely that training is not necessary. CPR training may seem more relevant to physicians at departments with high incidences of cardiac arrest compared with departments with lower incidences. However, CPR training may have an even greater impact on departments with lower incidence rates in the event of a cardiac arrest due to the lack of experience with resuscitation.

Study participants pointed towards new initiatives to improve CPR training, including e-learning, short booster sessions (high-dose low-frequency training) and use of an annual course day without clinical obligations in order to complete CPR training. E-learning has been shown to be an effective alternative to BLS training for laypersons ${ }^{16}$ and a cost-effective way to shorten the duration of ALS training. ${ }^{17,32}$ E-learning has several advantages such as allowing course participants to use learning material at their own pace. ${ }^{33}$ However, not all studies report e-learning to be equally efficient compared to standard CPR training ${ }^{32}$ and many learners prefer face-to-face teaching over e-learning without face-to-face training. ${ }^{33}$ This may be reflected in the finding that half of participants did not report e-learning to increase their attendance. The request for face-to-face teaching should also be considered when using self-training, which was preferred by less than a third of participants in this study. Self-training is known to be efficient for training, eg chest compressions, ${ }^{34}$ but may be less efficient when compared to instructor-led feedback. ${ }^{18}$ Moreover, selftraining is not usable for training of non-technical skills, which are known to be a determinant of CPR quality ${ }^{35}$ and also a barrier for improving in-hospital resuscitation. ${ }^{36}$ Accordingly, self-training may not be able to stand alone as a CPR training method. 
The use of short booster sessions (low-dose highfrequency training) was among the popular initiatives to improve course participation. A number of recent studies have shown that low-dose high-frequency training is highly efficient for avoiding skill decay and even improving CPR skills. $^{12,18,37-39}$ In clinical practice, short booster sessions can be carried out as a brief training session on BLS skills performed on a manikin or as an in-situ simulated cardiac arrest ("mock codes"). The use of mock codes may improve CPR performance and perceived confidence levels for nurses ${ }^{40}$ and enable identification of targets for further educational interventions. ${ }^{41}$ Furthermore, a recent study found an association between the use of mock codes and improved survival rates following IHCA. ${ }^{42}$

The most popular approach suggested to improve CPR training participation was an annual day for CPR training without clinical obligations. This solution may solve problems of signing up for courses and poor awareness. However, recertification of CPR skills could be combined with other mandatory recertification skills (eg firefighting or other mandatory skills) for one day and several days must be found for each group of physicians in order to maintain performance of clinical tasks in the departments. Nonetheless, an annual course day does not solve the problem of skill decay after only a few months.

\section{Limitations}

This is a questionnaire study, and the actual change in CPR course attendance based on new CPR training initiatives is unknown. We assessed barriers and initiatives to improve training using pre-specified closed questions. We do not know whether different barriers and different initiatives would evolve from using open-ended narrative comments. We did not include all physicians at each department as we sampled physicians at only one morning staff meeting in each department. However, this is a "random" sample, and we have no reason to believe that this sample is different from physicians at the same departments not attending this morning staff meeting. Our response rate from this "random" sample is $92 \%$, considered a high response rate. We cannot infer on other professions such as nurses, and we cannot infer on physicians from departments not included in this study, eg Department of Anesthesiology and Intensive Care. Not all physicians reported time since the last CPR training and some physicians did not respond at all. Physicians not responding may have attended CPR training less frequently. The response rate is high, which minimizes selection bias.

\section{Conclusion}

One-third of physicians did not attend hospital CPR training at two Danish hospitals. Several barriers to course participation exist, of which course registration seems to be a crucial factor. Alternative CPR training methods may help improve training participation.

\section{Acknowledgment}

We thank all physicians who volunteered to answer the questionnaires. We thank the resuscitation officers Leif Bach, MD, Tabita Gallagher, RN, and Jacob Løyche, RN for validation of questionnaires. The abstract of this paper was presented at the American Heart Association Resuscitation Science Symposium 2016 as a poster presentation with interim findings. The poster's abstract was published in Circulation. 2016; 134:A20463.

\section{Funding}

There is no funding to report.

\section{Disclosure}

The authors of this manuscript declare no conflicts of interest.

\section{References}

1. Ehlenbach WJ, Barnato AE, Curtis JR, et al. Epidemiologic study of in-hospital cardiopulmonary resuscitation in the elderly. $N$ Engl $\mathrm{J} \mathrm{Med}$. 2009;361(1):22-31. doi:10.1056/NEJMoa0810245

2. Girotra S, Nallamothu BK, Spertus JA, Li Y, Krumholz HM, Chan PS. Trends in survival after in-hospital cardiac arrest. $N$ Engl $J$ Med. 2012;367(20):1912-1920. doi:10.1056/NEJMoa1109148

3. Andersen LW, Holmberg MJ, Berg KM, Donnino MW, Granfeldt A. In-hospital cardiac arrest: a review. JAMA. 2019;321(12):1200-1210. doi:10.1001/jama.2019.1696

4. Andersen LW, Ostergaard JN, Antonsen S, et al. The Danish in-hospital cardiac arrest registry (DANARREST). Clin Epidemiol. 2019;11:397-402. doi:10.2147/CLEP.S201074

5. Sandroni C, Nolan J, Cavallaro F, Antonelli M. In-hospital cardiac arrest: incidence, prognosis and possible measures to improve survival. Intensive Care Med. 2007;33(2):237-245. doi:10.1007/s00134-0060326-z

6. Abella BS, Sandbo N, Vassilatos P, et al. Chest compression rates during cardiopulmonary resuscitation are suboptimal: a prospective study during in-hospital cardiac arrest. Circulation. 2005;111 (4):428-434. doi:10.1161/01.CIR.0000153811.84257.59

7. Abella BS, Alvarado JP, Myklebust H, et al. Quality of cardiopulmonary resuscitation during in-hospital cardiac arrest. JAMA. 2005;293 (3):305-310. doi:10.1001/jama.293.3.305

8. Chamberlain DA, Hazinski MF, Council ER, et al. Education in resuscitation: an ILCOR symposium: Utstein Abbey: Stavanger, Norway: June 22-24, 2001. Circulation. 2003;108(20):2575-2594. doi:10.1161/01.CIR.0000099898.11954.3B

9. Soreide E, Morrison L, Hillman K, et al. The formula for survival in resuscitation. Resuscitation. 2013;84(11):1487-1493. doi:10.1016/j. resuscitation.2013.07.020 
10. Cheng A, Nadkarni VM, Mancini MB, et al. Resuscitation education science: educational strategies to improve outcomes from cardiac arrest: a scientific statement from the American Heart Association. Circulation. 2018;138. doi:10.1161/CIR.0000000000000583

11. Chan PS, Krein SL, Tang F, et al. Resuscitation practices associated with survival after in-hospital cardiac arrest: a nationwide survey. JAMA Cardiol. 2016;1(2):189-197. doi:10.1001/jamacardio.2016. 0073

12. Woollard M, Whitfield R, Newcombe RG, Colquhoun M, Vetter N, Chamberlain D. Optimal refresher training intervals for AED and CPR skills: a randomised controlled trial. Resuscitation. 2006;71 (2):237-247. doi:10.1016/j.resuscitation.2006.04.005

13. Chamberlain D, Smith A, Woollard M. Trials of teaching methods in basic life support: comparison of simulated CPR performance after first training and at 6 months, with a note on the value of re-training. Resuscitation. 2002;26:218-227.

14. Sullivan NJ, Duval-Arnould J, Twilley M, et al. Simulation exercise to improve retention of cardiopulmonary resuscitation priorities for in-hospital cardiac arrests: a randomized controlled trial. Resuscitation. 2015;86:6-13. doi:10.1016/j.resuscitation.2014.10.021

15. Skrifvars MB, Castren M, Kurola J, Rosenberg PH. In-hospital cardiopulmonary resuscitation: organization, management and training in hospitals of different levels of care. Acta Anaesthesiol Scand. 2002;46(4):458-463. doi:10.1034/j.1399-6576.2002.460423.x

16. Einspruch EL, Lynch B, Aufderheide TP, Nichol G, Becker L. Retention of CPR skills learned in a traditional AHA Heartsaver course versus 30-min video self-training: a controlled randomized study. Resuscitation. 2007;74(3):476 486. doi:10.1016/j.resuscitation.2007.01.030

17. Thorne CJ, Lockey AS, Bullock I, Hampshire S, Begum-Ali S, Perkins GD. E-learning in advanced life support-an evaluation by the Resuscitation Council (UK). Resuscitation. 2015;90:79-84. doi:10.1016/j.resuscitation.2015.02.026

18. Sutton RM, Niles D, Meaney PA, et al. Low-dose, high-frequency CPR training improves skill retention of in-hospital pediatric providers. Pediatrics. 2011;128(1):e145-e151. doi:10.1542/peds.2010-2105

19. Schmidt AS, Lauridsen KG, Adelborg K, Løfgren B. Hospital implementation of resuscitation guidelines and review of CPR training programmes: a nationwide study. Eur J Emerg Med. 2016;23 (3):232-234. doi:10.1097/MEJ.0000000000000296

20. Andersen LW, Holmberg MJ, Lofgren B, Kirkegaard H, Granfeldt A. Adult in-hospital cardiac arrest in Denmark. Resuscitation. 2019;140:31-36. doi:10.1016/j.resuscitation.2019.04.046

21. Lauridsen KGG, Løfgren B. A call for 2222 in European hospitalsA reply to letter by Dr. Whitaker. Resuscitation. 2016;107:e19. doi:10.1111/joor. 12353

22. Lauridsen KG, Schmidt AS, Adelborg K, Løfgren B. Organisation of in-hospital cardiac arrest teams - A nationwide study. Resuscitation. 2015;89(C):123-128. doi:10.1016/j.resuscitation.2015.01.014

23. Lauridsen KG, Krogh K, Müller SD, et al. Barriers and facilitators for in-hospital resuscitation: a prospective clinical study. Resuscitation. 2021;164:70-78. doi:10.1016/j.resuscitation.2021.05.007

24. Hunt EA, Duval-Arnould JM, Chime NO, et al. Integration of in-hospital cardiac arrest contextual curriculum into a basic life support course: a randomized, controlled simulation study. Resuscitation. 2017;114:127-132. doi:10.1016/j.resuscitation.2017.03.014

25. Madden C. Undergraduate nursing students' acquisition and retention of CPR knowledge and skills. Nurse Educ Today. 2006;26 (3):218-227. doi:10.1016/j.nedt.2005.10.003

26. Cheng A, Magid DJ, Auerbach M, et al. Part 6: resuscitation education science: 2020 American Heart Association guidelines for cardiopulmonary resuscitation and emergency cardiovascular care. Circulation. 2020;142(16_suppl_2):S551-S579. doi:10.1161/ CIR.0000000000000903
27. Greif R, Lockey A, Breckwoldt J, et al. European resuscitation council guidelines 2021: education for resuscitation. Resuscitation. 2021;161:388-407. doi:10.1016/j.resuscitation.2021.02.016

28. Greif R, Bhanji F, Bigham BL, et al. Education, implementation, and teams: 2020 international consensus on cardiopulmonary resuscitation and emergency cardiovascular care science with treatment recommendations. Circulation. 2020;156. doi:10.1016/j. resuscitation.2020.09.014

29. Lauridsen KG, Schmidt AS, Caap P, Aagaard R, Løfgren B. Clinical experience and skills of physicians in hospital cardiac arrest teams in Denmark: a nationwide study. Open Access Emerg Med. 2017;9:37-41. doi:10.2147/OAEM.S124149

30. Siebig S, Kues S, Klebl F, et al. Cardiac arrest: composition of resuscitation teams and training techniques: results of a hospital survey in German-speaking countries. Dtsch Arztebl Int. 2009;106 (5):65-70. doi:10.3238/arztebl.2009.0065

31. Hopstock LA. Motivation and adult learning: a survey among hospital personnel attending a CPR course. Resuscitation. 2008;76 (3):425-430. doi:10.1016/j.resuscitation.2007.09.011

32. Perkins GD, Kimani PK, Bullock I, et al. Improving the efficiency of advanced life support training: a randomized, controlled trial. Ann Intern Med. 2012;157(1):19-28. doi:10.7326/0003-4819-157-1-20120703000005

33. Lockey AS, Dyal L, Kimani PK. Electronic learning in advanced resuscitation training: the perspective of the candidate. Resuscitation. 2015;97:48-54. doi:10.1016/j.resuscitation.2015.09.391

34. Lynch B, Einspruch EL, Nichol G, Becker LB, Aufderheide TP, Idris A. Effectiveness of a 30-min CPR self-instruction program for lay responders: a controlled randomized study. Resuscitation. 2005;67(1):31-43. doi:10.1016/j.resuscitation.2005.04.017

35. Marsch SC, Muller C, Marquardt K, Conrad G, Tschan F, Hunziker PR. Human factors affect the quality of cardiopulmonary resuscitation in simulated cardiac arrests. Resuscitation. 2004;60 (1):51-56. doi:10.1016/j.resuscitation.2003.08.004

36. Andersen PO, Jensen MK, Lippert A, Ostergaard D. Identifying non-technical skills and barriers for improvement of teamwork in cardiac arrest teams. Resuscitation. 2010;81(6):695-702. doi:10.1016/j.resuscitation.2010.01.024

37. Niles D, Sutton RM, Donoghue A, et al. "Rolling Refreshers": a novel approach to maintain CPR psychomotor skill competence. Resuscitation. 2009;80(8):909-912. doi:10.1016/j.resuscitation.2009.04.021

38. Niles DE, Nishisaki A, Sutton RM, et al. Improved retention of chest compression psychomotor skills with brief "rolling refresher" training. Simul Healthc. 2017;12(4):213-219. doi:10.1097/ SIH.0000000000000228

39. Patocka C, Cheng A, Sibbald M, et al. A randomized education trial of spaced versus massed instruction to improve acquisition and retention of paediatric resuscitation skills in emergency medical service (EMS) providers. Resuscitation. 2019;141:73-80. doi:10.1016/j.resuscitation.2019.06.010

40. Herbers MD, Heaser JA. Implementing an in situ mock code quality improvement program. Am J Crit Care. 2016;25(5):393-399. doi:10.4037/ajec2016583

41. Hunt EA, Walker AR, Shaffner DH, Miller MR, Pronovost PJ. Simulation of in-hospital pediatric medical emergencies and cardiopulmonary arrests: highlighting the importance of the first 5 minutes. Pediatrics. 2008;121(1):e34-e43. doi:10.1542/peds.2007-0029

42. Josey K, Smith ML, Kayani AS, et al. Hospitals with more-active participation in conducting standardized in-situ mock codes have improved survival after in-hospital cardiopulmonary arrest. Resuscitation. 2018;133:47-52. doi:10.1016/j.resuscitation.2018. 09.020 


\section{Publish your work in this journal}

The Open Access Emergency Medicine is an international, peerreviewed, open access journal publishing original research, reports, editorials, reviews and commentaries on all aspects of emergency medicine. The manuscript management system is completely online

and includes a very quick and fair peer-review system, which is all easy to use. Visit http://www.dovepress.com/testimonials.php to read real quotes from published authors.

Submit your manuscript here: https://www.dovepress.com/open-access-emergency-medicine-journal 